\title{
UN RECUERDO Y UN RENACIMIENTO
}

\author{
POR \\ JUAN ZOZAYA \\ Museo Arqueológico Nacional - c/ Serrano, 13 - 28001 Madrid
}

La reaparición de Gladius es un momento para retrotraer el recuerdo, para hacer memoria de los años que hace que conocí a su entusiasta y ya desaparecida fundadora, Ada Bruhn de Hoffmeyer, y el entusiasmo que puso siempre en su gran labor investigadora, pionera y animadora de otros «pionerismos» (perdóneseme el presunto neologismo). Requiere ahora un recuerdo, decía, pues su memoria debe ser ala del ánimo para el ahínco y esfuerzo personal que lucha contra todas las vicisitudes, contra los «hados» y a favor de los «improbables».

Conocí a Ada Bruhn y a su marido, «Fernando» Hoffmeyer, cuando acababa de volver de Nubia, adonde había colaborado como estudiante y trabajado con Pellicer y Presedo bajo la Dirección de Misión del Dr. Martín Almagro Basch. Fue entonces cuando empecé a juguetear con la idea de dedicarme a la arqueología medieval, por consejo de uno (Presedo) y por ayuda de Pellicer, que me habló de Manuel Casamar. El natural despiste del estudiante hizo desazonada presa en mí, pues no sabía muy bien por dónde empezar una disciplina que no tenía (ni tiene aún) mucho apoyo académico.

Los medios académicos y materiales eran pocos, a los, en mi caso particular había que añadir mi dependencia de los medios familiares, pues yo era entonces ciudadano colombiano. De todas maneras éramos relativamente pocos los que podíamos salir de una manera u otra del país, los libros extranjeros eran caros y no había muchos centros que pudieran contar con bibliogafía especializada en, por ejemplo, arqueología y arte islámicos. Todo se había quedado, prácticamente, en este campo, en donde lo había dejado D. Manuel Gómez Moreno.

El ambiente académico del momento no era muy estimulante para quien no deseara seguir los caminos trillados por la «academia oficial». Gran parte de los exiliados como consecuencia de la Guerra Civíl (1936-1939) continuaban fuera, la censura intelectual era algo normal y las posibilidades de viajar al exterior, ver lo que se hacía en nuestros paises vecinos, era algo fuera del alcance del estudiante normal. Pocos eran los profesores que estimulaban al estudiante por caminos nuevos, y la filosofía «oficial» no solía llegar a Kant.

Mi madre sugirió que fuera a visitar el Museo del Instituto Valencia de Don Juan, lugar que ella había conocido a instancias de uno de sus maestros, D. Manuel Gómez Moreno. Ahí, pues, decidí dirigir mis pasos con una aspiración simple: ¿Podría visitar las colecciones? ¿Admitirían que un estudiante pudiese dibujar sus fondos cerámicos como práctica gratuita? En fin, cargado de dudas toqué el timbre del palacete de la calle Fortuny. Atanasio González, el gran Atanasio, me abrió la puerta, me dijo que habría que preguntar, me mostró la colección, me hizo toda suerte de preguntas y me indicó que había una persona estudiando la cerámica, que resultó ser Manuel Casamar. Aquí se originan varias historias bellas de mi vida. Una de ellas trajo la otra. 
En efecto: Manuel Casamar, de quien mucho me había hablado Manuel Pellicer, me ayudó a poder acceder a dibujar cerámica y aprender sobre ella con su tutela. Pasé a dibujar cerámica de reflejo dorado de Manises para un catálogo que tenía encargado, y con ello pasé a ir al Instituto dos o tres tardes por semana a familiarizarme con dicho material, labor que realicé durante casi un año entero. Un privilegio trajo otro.
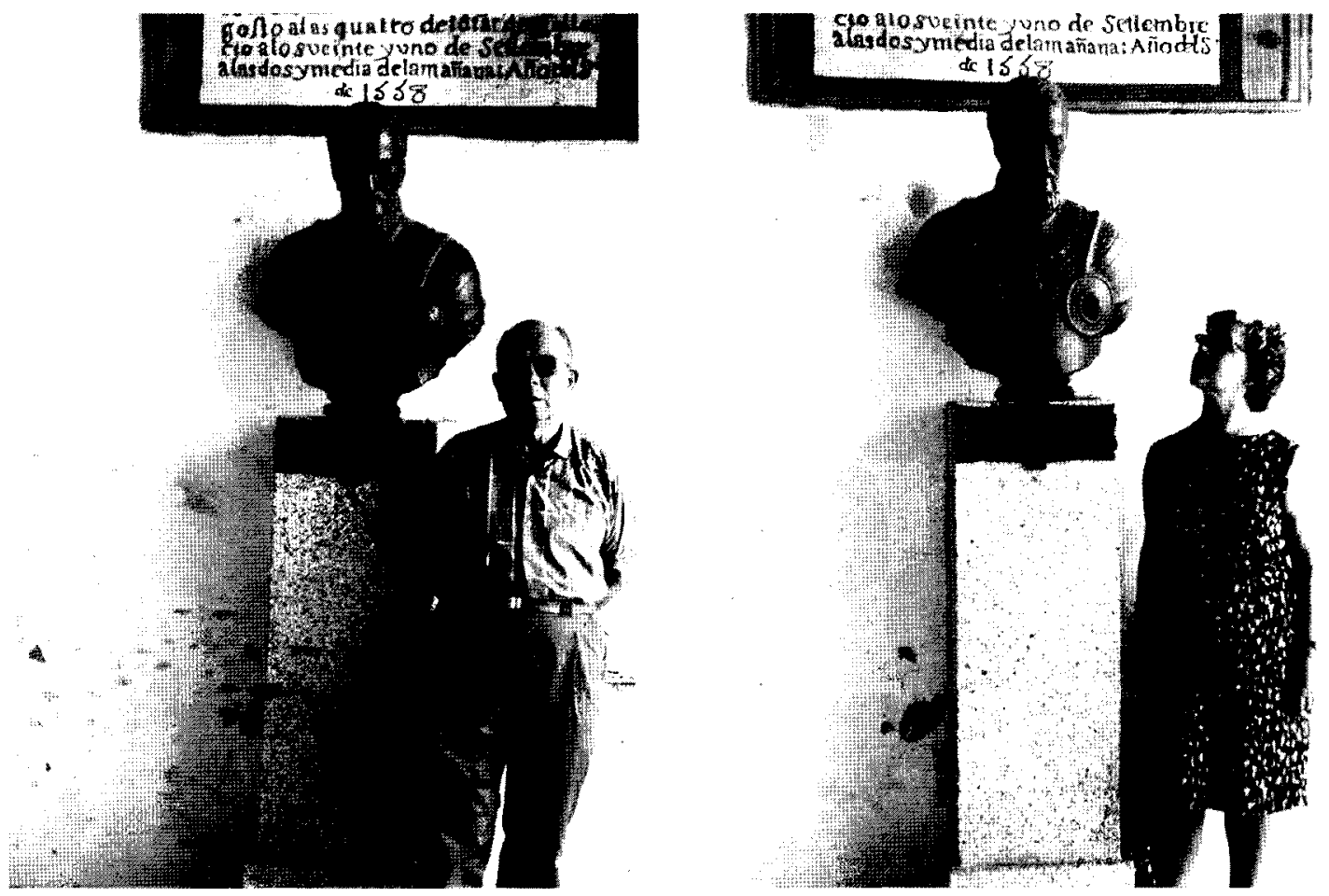

Erling Hoffmeyer y Ada Bruhn en el Palacio de Yuste.

En efecto, el primero era el poder acudir a tan selecto lugar a aprender con tan buen guía. El segundo fue que, como consecuencia del ambiente de trabajo serio y retirado, pude tener el de conocer a otras personas como D. Pedro Longás, a la sazón Director del centro, a D. Antonio Floriano, su archivero y al matrimonio Hoffmeyer. Éste era, sin duda el elemento más «exótico» de todos. Fue una convivencia con una serie de personas importantes en mi vida de alevín de investigador, todos ellos por su seriedad, y, como alguien comentó recientemente refiriéndose a quienes ahí trabajan «sin celos ni envidias, ya que todos estaban jubilados».

No puedo pensar que fuera así, pues todas ellas fueron personas de generosidad ejemplar, y dudo que fuera una virtud adquirida, sin excepción, como consecuencia de la edad proyecta. Pronto trabé amistad con el matrimonio danés, quizás en parte impulsado por nuestras comunes raíces escandinavas. El era bastante menos comunicativo, pero Ada, la persona que ahora deseo traer a colación, fue siempre una maravillosa comunicadora.

El primer rasgo que llamaba la atención era su figura. Un ejemplo de nórdica de periferia urbana escandinava, acostumbrada a las labores domésticas de quien vive en casa aislada (fenómeno social que entonces casi no llegaba a España), enérgica, de buen ánimo. Su presencia me dio ánimos, pues su inmensa humanidad (ien ambos sentidos!) me animaba en el camino recién abierto, y ponía su propio ejemplo: interesada en ayudar a su marido, reali- 
zando su investigación independiente de él, posteriormente viniéndose a España en 1962 para trabajar «huyendo» de los climas nórdicos, trasladando la revista que habían fundado en Dinamarca, con sus consiguientes problemas de financiación, eran muestra de cómo superarlos. Su ejemplo continuó años después, en fin, yéndose a Jaraíz de la Vera, en un voluntario y fructuoso «autoexilio» que fue un ejemplo de trabajo y dedicación en el cual las dificultades físicas no fueron jamás un obstáculo.

Siempre alegre, hasta prácticamente el último momento, queda como un ejemplo de generosidad con los demás, de trabajo y dedicación, haciendo sus paquetes, llevándolos al correo tras cargarlos ella misma en su coche y dando siempre recuerdos para sus amigos de Madrid. Siempre me llegaron de la mano de nuestro común discípulo (espero que él, con su gran amistad hacia mi, me perdone este trato) Alvaro Soler, asiduo visitante a su centro de Jaraiz.

Los años pasaron, tras su muerte, con querencia de olvido, y ni su lápida en el cementerio mereció muchas atenciones por parte de sus beneficiados, un tanto incapaces de comprender el tesoro que tenían (y tienen) entre sus manos. Personalmente me preocupó mucho el destino de la biblioteca, una de las mejores de su género, la mejor y única de España, y la falta de comprensión de unas autoridades no demasiado generosas con quien tanto entregaba.

Afortunadamente ahora la situación se altera, y la biblioteca y el Instituto, cual fénix, parecen volver a vivir, con gente joven, con empuje que aparece bajo, la si no flamígera figura de Ada en su extremeña tierra de adopcion, si bajo el manto de su gran humanidad, con su magnifico puro, con su jocundidad y al volante de su viejo Renault, llevando su carga de ciencia al correo y uniendo a todos en la generosa universalidad de la investigación...

Madrid, 23 de diciembre de 1998 